\title{
PERCEPTIONS OF ENGLISH LANGUAGE PRIMARY SCHOOL TEACHERS IN VIETNAM TOWARDS THE IMPLEMENTATION OF ENGLISH AS A MEDIUM OF INSTRUCTION
}

\author{
Duy Truong \\ College of Arts and Education, Victoria University, Melbourne (Australia)
}

\begin{abstract}
The implementation of English as a medium of instruction (EMI) in English-as-a-foreign-language (EFL) classrooms is beneficial to the amelioration of students' English skills. It is assumed that the earlier EMI is engaged in teaching, the more effectively English language students can enhance their skills. Because of this assumption, EMI is being implemented in many EFL classrooms, starting from primary schools. Recently, Vietnamese primary school teachers of English have been encouraged by the Ministry of Education and Training (MOET) to implement more EMI in their classrooms with the belief that its implementation helps students develop their communicative competence, contributing to the realisation of making English as a competitive advantage for Vietnamese high school/college/university graduates by the year of 2020 .

Teachers' implementation of EMI depends on many factors, one of which is their perceptions of EMI. This study surveyed English language primary school teachers about their perceptions towards the implementation of EMI in their EFL classrooms. 311 teachers from three provinces in southern Vietnam took part in an online questionnaire. Findings elicit that the majority of English language primary school teachers possessed a positive perception towards the benefits of the implementation of EMI to students such as: English language proficiency improvement, better interaction, cost-effectiveness for their learning, etc. Further, teachers admitted that the implementation of EMI can help themselves as well. They felt the need to participate in innovative English teaching methodologies, skill training as well as sharing sessions on the implementation of EMI. They recommended that in order to help them successfully implement EMI in their EFL classrooms, the facility need to be invested and the class size be smaller.
\end{abstract}

Keywords: EMI, perceptions, implementation of EMI.

\section{Introduction}

Currently, English is regarded as a dominant, international language used in multiple fields of education, business, trade, and culture because it facilitates access to knowledge as well as worldwide information (Crystal, 2012). Because of its popularity and the manner in which it empowers people, English language has become a compulsory subject in most non-native English speaking countries and their schools (Dearden, 2015). According to Kirkpatrick (2011) and Nguyen (2011), there is a tendency that students begin learning English at a younger age and Vietnam is no exception. Dang, Nguyen and Le (2013) indicate that since English has become more universally engaged, the demand for English language proficiency is increasingly developing and there are more schools in which EMI is under implementation to meet the diverse needs of language learners in Vietnam. Under Vietnam's National Foreign Language 2020 (NFL2020) initiated by the Vietnamese government, since 2008, many English language teachers throughout the country have participated in professional development training workshops and seminars on the use of EMI. As stipulated from Vietnam's MOET, EMI is now being encouraged to be used in EFL classrooms from basic to higher education in Vietnam; however, very little research in Vietnam has been gathered to explore English language teachers' perceptions towards the implementation of EMI and this is especially in the use of EFL in primary schools. Therefore, this study aimed to investigate the perceptions and attitudes of English language primary school teachers towards the adoption of EMI in Vietnam. Developing an evidentiary basis for understanding English language teachers' perceptions towards the implementation of EMI in primary schools will help Vietnam's MOET, NFL2020 Project Managing Board and provincial leaders of Departments of Education and Training 
(DOETs) to develop customised teacher-training on the adoption of EMI which is more beneficial to the primary teachers of English, contributing to the establishment of professional learning communities in Vietnam.

\section{Literature review}

Literature elicits that EFL teachers' positive perceptions and attitudes towards professional development training influence their successful teaching performance (Al-Seghayer, 2014; Truong, 2015a; 2015b). So, it can be implied that should teachers possess positive perceptions towards the use of EMI, they will offer to manipulate it in their EFL classrooms if obliged to do so (Corrales, Paba Rey \& Escamilla, 2016). Otherwise, they will have the feeling of being compelled to implement EMI as an act of compliance, which may lead to less favourable outcomes in the classrooms. The EFL students may also suffer. Besides those in favour of EMI and those opposed to its implementation, there are teachers who are ambivalent and unsure of the effectiveness of EMI or L1 use. The literature would indicate that these three positions and the perceptions of EFL teachers towards the adoption of EMI could be labelled as 'positive', 'ambivalent' or 'negative'.

Research denotes that the discernments of teachers, students, parents and researchers towards the implementation of EMI are positive (Al-Qahtani \& Al Zumor, 2015; Corrales et al, 2016; Kim, Kweon \& Kim, 2017). Apart from the positive perceptions, in a study conducted addressing EMI in China, Hu (2016) concludes that some teachers have a very ambivalent perception towards the use of EMI in their classrooms. They are satisfied with their English and they believe that their English is sufficient to carry out assigned teaching goals. However, they also express their concern about the implementation of EMI due to the lack of support as well as challenges for both teaching and learning that they cope with in their daily teaching performance. They believe that the government needs to support them during the process of their implementation of EMI. Quite different to previous studies, discernments of many teachers and students towards the implementation of EMI are negative (Jiang, Zhang \& May, 2016; Kim et al, 2017; Sali, 2014).

To sum up, teachers possess mixed perceptions towards the implementation of EMI in their classrooms. However, as confirmed by Dearden and Macaro (2016), English language levels of teachers may impact on their attitudes to EMI. Therefore, to help English language teachers possess a positive perception towards the implementation of EMI, their English levels have to be improved and they need to believe in the genuine benefits that the implementation of EMI brings to their students and themselves.

\section{Methodology}

An online questionnaire was utilised because of its convenience for research participants to readily access (Evans \& Mathur, 2005). More importantly, it could help reach many participants from different areas at a time (Selm \& Jankowski, 2006). This study's online questionnaire surveyed 600 English language primary school teachers from three provinces which represent three different developmental areas in southern Vietnam.

\section{Findings}

From the hyperlink sent to 600 English language primary school teachers to gather both quantitative and qualitative data (200 teachers in each province), 311 teachers responded, yielding a response rate of $51.83 \%$.

\subsection{Demographics and information from research participants}

Of 311 teachers taking part in this online questionnaire, $70.4 \%$ were female and $29.6 \%$ were male. Regarding the highest qualifications which English language primary school teachers obtained, the majority of the respondents $(n=233,74.9 \%)$ had a Bachelor degree while 75 out of $311(24.1 \%)$ earned their College degree. A very small number had obtained a Master degree $(n=2)$ or other certificates $(\mathrm{n}=1)$ (see Table 1$)$. 
Table 1. Highest qualifications teachers obtained in three provinces.

\begin{tabular}{|ll|r|r|r|r|}
\hline & & & Cumulative \\
Valid & College degree & 75 & 24.1 & Palid Percent & \multicolumn{2}{|c|}{ Percent } \\
& Bachelor degree & 233 & 74.9 & 24.1 & 24.1 \\
Master degree & 2 & .6 & 74.9 & 99.0 \\
Other & 1 & .3 & .6 & 99.7 \\
Total & 311 & 100.0 & .3 & 100.0 \\
\hline
\end{tabular}

Table 2 illustrates that teachers taking part in the online questionnaire were quite experienced in primary school English teaching. 207 out of 311 teachers had from 4 to more than 6 years of teaching English in primary schools, which accounted for $66.6 \%$ of the entire respondents as compared to $30.5 \%$ of teachers who had from 1 to less than 4 years. Only 9 out of $311(2.9 \%)$ lacked experience of primary school English teaching (with less than one year).

Table 2. English language teaching experience in primary schools of teachers in three provinces.

\begin{tabular}{|c|c|c|c|c|c|}
\hline & & Frequency & Percent & Valid Percent & $\begin{array}{c}\text { Cumulative } \\
\text { Percent }\end{array}$ \\
\hline \multirow[t]{5}{*}{ Valid } & $<1$ & 9 & 2.9 & 2.9 & 2.9 \\
\hline & 1 to $<4$ & 95 & 30.5 & 30.5 & 33.4 \\
\hline & 4 to 6 & 96 & 30.9 & 30.9 & 64.3 \\
\hline & $>6$ & 111 & 35.7 & 35.7 & 100.0 \\
\hline & Total & 311 & 100.0 & 100.0 & \\
\hline
\end{tabular}

\subsection{EFL primary school teachers' perceptions towards the benefits of the implementation of EMI to students}

Of all the 311 teachers' responses, more than $85 \%$ of the teachers showed the benefits which EMI brought to their EFL primary school students. Specifically, primary school teachers of English expressed their two levels of agreement (agreement or strong agreement) with the belief that the adoption of EMI helps primary school students. They stated the benefits to:

(1) generally improve students' English skills efficiently (95.5\%);

(2) enhance students' English language proficiency (95.5\%);

(3) maximise students' exposure to English (92.6\%);

(4) better students' listening skills ( $88.5 \%)$;

(5) better students' speaking skills (96.5\%);

(6) generally make students become more confident (94.8\%);

(7) interact with their EFL teachers and peers in English (92.6\%);

(8) practise students' thinking in English (93.9\%);

(9) memorise English words and lessons easily $(92.0 \%)$;

(10) improve students' pronunciation (86.9\%); and,

(11) become dynamic whilst still young English language learners (92.9\%).

Most teachers $(\mathrm{n}=241,77.5 \%)$ showed their agreement or strong agreement with the belief that the implementation of EMI helps EFL primary school students to engage more in-class EFL activities.

Overall, data shows that English language primary school teachers in the three surveyed provinces in southern Vietnam possessed a positive perception towards the benefits that the implementation of EMI brought to their students.

\subsection{EFL primary school teachers' perceptions towards the benefits of the implementation of EMI to themselves}

Of 311 teachers' responses, more than $80 \%$ of the teachers indicated that they had positive perceptions towards the benefits of the implementation of EMI to themselves. They also expressed their two levels of agreement (agreement and strong agreement) with the benefits of the implementation of EMI. Specifically, the implementation of EMI:

(1) made themselves more confident English language teachers in their classrooms (93.9\%);

(2) made them practise their English everyday (96.7\%);

(3) was cost-effective for their learning $(94.5 \%)$;

(4) required that they spend more time preparing their lessons (83.3\%); 
(5) developed their own English language proficiency (95.8\%); and,

(6) highly motivated them to improve their teaching skill (96.2\%).

However, less than $60 \%$ of teachers $(58.8 \%)$ expressed their agreement or strong agreement with the belief that the implementation of EMI helped the creation of an authentic English environment for them as EFL teachers.

In summary, the data demonstrates that the majority of English language primary school teachers in the three surveyed provinces in southern Vietnam possessed a positive perception towards the benefits that the implementation of EMI brought to themselves. They shared relatively similar opinions about the merits to themselves when engaging with EMI in their EFL classrooms.

\subsection{Implications for teachers implementing EMI in EFL primary school classrooms in Vietnam}

The question relating to teachers' implications for their implementation of EMI in EFL primary school classrooms in Vietnam was optional because the researcher did not expect participants to leave the online questionnaire unfinished. Of 311 participants taking in part in the online questionnaire, only 53 teachers responded to this question, accounting for $17.0 \%$. Below are teachers' implications of the implementation of EMI in EFL primary school classrooms in Vietnam.

4.4.1. Enhancement of teacher professional development training on the use of EMI. $30.2 \%$ of teachers $(n=16)$ responded that teachers should be offered more opportunities to attend training on the implementation of EMI. At the inception, teachers commented that the implementation of EMI is very important because it helps:

(1) improve students' oral skills $(n=7)$;

(2) create an English-speaking environment for students in the classrooms $(n=6)$;

(3) ameliorate teachers' English $(\mathrm{n}=5)$; and, $(\mathrm{n}=4)$.

(4) build students' confidence in using English to communicate with their peers and teachers

Other teachers indicated that the implementation of EMI helps (1) enhance the quality of teaching and learning English; (2) interact effectively between students and teachers as well as between students and their peers; and, (3) improve students' thinking in English.

Teachers also pointed out that their opportunities to engage in trainings on the use of EMI were to be provided by their units of education, DOETs and MOET.

Six out of 16 teachers mentioned the need of the training on English teaching methodologies in their responses. They expressed their hope to gain more English teaching skills via the training and to have opportunities to apply what was trained in their EFL primary school classrooms. Half of the teachers $(\mathrm{n}=3)$ asserted their needs to attend trainings on innovative English teaching methodologies which were more applicable in their classrooms to stimulate students' interests in their studies rather than regular sessions that were heavily theory-based.

Four out of 16 teachers highlighted the training on skills when EMI was under implemented in their classrooms. They wanted to be provided with chances to practise specific skills trained from the training.

Two out of 16 teachers suggested that sharing sessions between teachers and teachers on the implementation of EMI should be conducted regularly so that teachers could study from each other. They were also opportunities for teachers to share with their colleagues experiences as well as challenges they might encounter when EMI was under implementation in their classrooms.

4.4.2. Facility investment. More than one fourths of the teachers $(n=14,26.4 \%)$ pointed out that facilities in schools and classrooms had to be upgraded so that teachers' implementation of EMI could be more possible. Teachers indicated that many schools in Vietnam, especially those in rural areas did not have enough facilities as well as function rooms for English language teachers. They wrote that even if schools did have function rooms, they were not designed specifically for English language teaching. Besides, softwares and teaching aids for English language teachers like pictures, flashcards, realia, etc. had to be invested as they helped boost students' English learning when EMI was under implementation.

4.4.3. Smaller class size. $22.6 \%$ of teachers $(n=12)$ indicated that class size was one of the problems which hindered their implementation of EMI in classrooms. They pointed out the following challenges when EMI was implemented in big class size.

(1) They found it hard to observe students and check students' language practice.

(2) Big class size lessened the quality of English language teaching and learning.

(3) Big class size exhausted teachers as it took away their energy for teaching. 


\section{Conclusion}

Findings elicit that the majority of English language primary school teachers in the three different provinces in southern Vietnam possessed a positive perception towards the benefits of the implementation of EMI to students such as: English language proficiency improvement, better interaction, cost-effectiveness for their learning, etc. Further, teachers admitted that the implementation of EMI can help themselves as well. They felt the need to participate in innovative English teaching methodologies, skill training as well as sharing sessions on the implementation of EMI. They recommended that in order to help them successfully implement EMI in their EFL classrooms, the facility need to be invested and the class size be smaller.

\section{References}

Al-Seghayer, K. (2014). The four most common constraints affecting English teaching in Saudi Arabia. International Journal of English Linguistics, 4(5),17-26.

Al-Qahtani, Z. \& Al Zumor, A. (2016). Saudi parents' attitudes towards using English as a medium of instruction in private primary schools. International Journal of Applied Linguistics and English Literature, 5(1), 18-32.

Corrales, K., Paba Rey, L. \& Escamilla, N. (2016). Is EMI enough? Perceptions from university professors and students. Latin American Journal of Content and Language Integrated Learning, 9(2), 318-344.

Crystal, D. (2012). English as a global language. Cambridge University Press, New York.

Dang, A., Nguyen, H. \& Le, T. (2013). The impacts of globalisation on EFL teacher education through English as a medium of instruction: an example from Vietnam. Current Issues in Language Planning, 14(1), 52-72.

Dearden, J. (2015). English as a medium of instruction - a growing global phenomenon. British Council, United Kingdom.

Dearden, J. \& Macaro, E. (2016). Higher education teachers' attitudes towards English medium instruction: a three-country comparison. Studies in Second Language Learning and Teaching, 6(3), 455-486.

Evans, J. \& Mathur, A. (2005). The value of online surveys. Internet research, 15(2), 195-219.

$\mathrm{Hu}$, L. (2016). Content teachers' perceptions towards EMI in Chinese universities. Intercultural Communication, 429-446.

Jiang, L., Zhang, L. \& May, S. (2016). Implementing English medium instruction (EMI) in China: teachers' practices and perceptions, and students' learning motivation and needs. International Journal of Bilingual Education and Bilingualism, 1-13.

Kim, E., Kweon, S. \& Kim, J. (2017). Korean engineering students' perceptions of English-medium instruction (EMI) and L1 use in EMI classes. Journal of Multilingual and Multicultural Development, 38(2), 130-145.

Kirkpatrick, A. (2011). English as a medium of instruction in Asian education (from primary to tertiary): implications for local languages and local scholarship. Applied Linguistics Review, 2(11), 99-119.

Nguyen, H. (2011). Primary English language education policy in Vietnam: insights from implementation. Current Issues in Language Planning, 12(2), 225-249.

Sali, P. (2014). An analysis of the teachers' use of L1 in Turkish EFL classrooms', System, 42, 308-318.

Selm, M. \& Jankowski, N. (2006). Conducting online surveys. Quality and Quantity, 40(3), 435-456.

Truong, D. (2015a). The effects of teacher professional development on teaching practice and student learning outcome. International Journal for Educational Studies, 7(2), 181-188.

Truong, D. (2015b). Teacher professional development. Education India Journal: A Quarterly Refereed Journal of Dialogues on Education, 4(3), 111-130. 